UNIVERSIDADE DE SÃO PAULO

INSTITUTO DE PSICOLOGIA

LUCY DURÓ MATOS ANDRADE SILVA

Reflexões sobre a Educação Crítica e Emancipadora:

o Projeto Âncora em questão 


\section{Reflexões sobre a Educação Crítica e Emancipadora: o Projeto Âncora em questão}

\section{Versão Corrigida}

Dissertação Apresentada ao Instituto de Psicologia da Universidade de São Paulo para obtenção de título de Mestre em Psicologia.

Área de Concentração: Psicologia Escolar e do Desenvolvimento Humano.

Orientadora: Prof ${ }^{\text {a }} \mathrm{Dr}^{\mathrm{a}}$ Marilene Proença Rebello de Souza. 
Duró Matos Andrade Silva, Lucy

Reflexões sobre a Educação Crítica e Emancipadora: o Projeto Âncora em questão Lucy Duró Matos Andrade Silva; orientadora Marilene Proença Rebello de Souza. São Paulo, 2019.

$184 \mathrm{f}$.

Dissertação (Mestrado - Programa de Pós-Graduação em Psicologia Escolar e do Desenvolvimento Humano) -- Instituto de Psicologia, Universidade de São Paulo, 2019.

1. Projeto Âncora. 2. Escolas Democráticas. 3. Psicologia Escolar. 4. Educação. 5. Comunidades de Aprendizagem. I. Proença Rebello de Souza, Marilene, orient. II. Título. 
Nome: DURÓ Matos Andrade Silva, Lucy

Título: Reflexões sobre a Educação Crítica e Emancipadora: o Projeto Âncora em questão

Dissertação apresentada ao Instituto de Psicologia da Universidade de São Paulo para obtenção do título de Mestre em Psicologia.

Aprovada em:

Banca Examinadora

Profa. Dra. :

Instituição :

Julgamento:

Profa. Dra. :

Instituição :

Julgamento :

Prof. Dra. :

Instituição :

Julgamento : 
À minha mãe Luiza Duró Matos Pela dedicação de uma vida.

Aos meus filhos queridos, Gabi e Gui Pelo carinho, apoio e torcida de sempre.

À minha grande amiga e parceira Edileusa Santana Andrade. 


\section{AGRADECIMENTOS}

Antes de agradecer às pessoas importantes que estiveram ao meu lado para esta pesquisa acontecer, quero deixar registrado que um dos meus objetivos foi questionar as determinações dos padrões impostos socialmente. Costumo dizer que o ponto de interrogação é um instrumento que conduz nossa metamorfose. Não quero dizer, com isso, que convenções sociais não sejam importantes, todavia, segundo meu entendimento, a legitimidade de uma produção acadêmica se dá também pela subjetividade do pesquisador. Desse modo, vou quebrar a formalidade do politicamente correto e colocar aqui a minha gratidão a todos que foram, direta ou indiretamente, importantes para esta pesquisa acontecer. Todos! Não posso abrir mão, não seria coerente com a minha luta, superar os condicionamentos sociais e expressar aquilo que insisti tanto ao longo da pesquisa: o respeito às diferenças e a permissão de cada um ser o que realmente é. Esta sou eu!

Em primeiro lugar, eu agradeço à vida e a essa inteligência que está para além do que é possível à nossa pequenez alcançar, aquela que transcende nossa compreensão. Ao agradecer à vida, agradeço aos meus pais que me garantiram estar nela. Obrigada, pai, sei que em algum lugar você deve estar vibrando por eu ter chegado aqui, você foi uma referência de determinação e firmeza de caráter. Acompanhei sua trajetória de vida, de trabalho e a sua dedicação para deixar seu legado. Você continua vivo em mim, em nossa família, em amigos e pessoas com as quais conviveu e também, como negar, em algum lugar deste imenso Universo.

Obrigada, mãe, amiga querida, você que está e sempre esteve tão presente em minha vida. Agradeço pelo exemplo de valores morais e éticos que você nos transmitiu. Gratidão por todo apoio de sempre, sei que sem você esta minha conquista não teria sido possível. Você é e sempre será um exemplo para mim, exemplo de integridade, de mulher, de mãe, de cidadã que cumpriu seu papel social, familiar e afetivo de forma tão impecável e generosa. Você me ensinou a amar, perdoar, ser respeitosa com o próximo, reconhecer no outro a sua importância. Mãe, você me ensinou a ser mãe, a ser mulher. Você é uma grande referência de dignidade em minha vida! Dedico também este trabalho a você!

Obrigada, Re, um grande exemplo de dignidade e caráter. São quase 40 anos vividos juntos! Anos de convivência que trouxeram e continuam trazendo momentos desafiantes, alguns amargos, próprios de uma vida comum, e outros deliciosos de serem vividos com você, momentos que não negam a dialética que apresento ao longo do meu trabalho. Constituímos uma família e nos constituímos, enquanto pessoas, na relação com ela. Uma família linda em 
todos os sentidos, mas, principalmente, os relacionados aos valores morais e éticos, próprios da matriz axiológica, que tanto defendi ao longo do meu trabalho, nossas raízes! Nossos filhos nos trazem a sensação de termos feito o melhor que podíamos. Simplesmente íntegros e generosos! Gabi, filha querida, agradeço por todo seu apoio, compreensão, cumplicidade, carinho, dedicação, torcida. Você foi pessoa ímpar em um momento tão importante da minha vida, todas as palavras que eu usasse não seriam suficientes para lhe dedicar toda a minha gratidão. Você é uma das pessoas mais generosas que conheço. Obrigada pela sua dedicação a mim! Gratidão pela nossa parceria e amizade!

Gui, meu filho querido, do mesmo modo, agradeço por todo seu apoio, amizade, pelas palavras de encorajamento que tantas vezes ouvi da sua boca, obrigada pelo seu carinho, pela torcida, obrigada pela pessoa que você se tornou, agora, um pai de família dedicado, ao lado de uma pessoinha tão especial para mim, minha norinha querida, que eu tenho como terceira filha, pessoa carinhosa que está fazendo você muito feliz. Agradeço a você, Paloma, por se unir ao nosso Clã! Você é uma pessoa muito especial, que, juntamente com o Gui, me trouxe uma preciosidade, o pequeno Gregório (Greg para os íntimos), um bebezinho lindo que trouxe uma luz enorme para as nossas vidas. Assim como vocês, certamente, ele levará as sementes que plantamos!

Agradeço aos meus irmãos, Soninha e Celsinho, pelo incentivo e pela torcida de sempre!

Gratidão, Edileuza querida, minha grande amiga, parceira que enfrentou ao meu lado os maiores desafios da minha vida, um ser humano tão especial que eu não conheço outro igual. Digo isso porque é na dureza do cotidiano, na convivência, que conhecemos a luz e a sombra. Em você, Di, eu não vejo, absolutamente, sombra. Você é, para mim, uma grande referência e uma lição de vida que me inspira como o melhor que um ser Humano pode ter, por isso, você recebeu um lugar de destaque no meu trabalho.

Obrigada, minha querida tia Lene, pela torcida de sempre, também por estar presente em toda a minha vida, me trazendo tanta dedicação e carinho.

Obrigada, tia Gercy, querida! A senhora foi uma das responsáveis por eu estar aqui, agora, escrevendo estes agradecimentos! Onde a senhora estiver, saiba que também lhe dedico este trabalho!

Gratidão a vocês, minhas amigas queridas, de longa data, Celinha Nascimento, Rosana Abdo, Estela Alves, Nídia Regados, Meire Matos. Grandes companheiras nos momentos difíceis e parceiras de vida! 
Gratidão a todos os professores com os quais convivi em minha trajetória acadêmica, em especial, Prof ${ }^{\mathrm{a}}$. Dr ${ }^{\mathrm{a}}$. Ana Carla Cividanes Furlan Scarin, Prof ${ }^{\mathrm{a}}$. Dr ${ }^{\mathrm{a}}$. Maria Berenice Alho da Costa Tourinho, Prof ${ }^{a}$. Dr ${ }^{\mathrm{a}}$. Katia Cristina Forli Bautheney, Prof ${ }^{\mathrm{a}}$. Dr ${ }^{\mathrm{a}}$. Deborah Barbosa, Prof. Dr. Guillermo Arias Beatón, Prof. Dr. Vitor Henrique Paro.

Gratidão ao querido grupo de estudos sobre Vigotski e a Perspectiva Histórico-Cultural, em especial a Elenita de Rício Tanamachi, por me concederem tantas possibilidades de reflexão e de amadurecimento acadêmico. Do mesmo modo, gratidão às queridas colegas Ana Tejada, Célia Regina, Fernanda Rodrigues, Julia Bayer, Nancy Romanelli, Sabrina Gasparetti.

Gratidão ao querido Grupo de Orientandos, Aida Binze, Ana Gonzatto, Ana Maria Tejada, Daniele Gazzotti, Eduardo Frias, Eloisa, Gisele Costa, Marcia Justino, Mayte Albardía, Wanessa que tantas contribuições trouxeram para o enriquecimento do meu trabalho. Quero dedicar um agradecimento especial à minha querida amiga Christiane Jacqueline e ao amigo Felipe Oliveira! Gratidão pelas conversas, compreensão, aconselhamentos, carinho e respeito que vocês dedicaram a mim ao longo do meu percurso! Vocês foram grandes parceiros e amigos!

Agradeço ao Instituto de Psicologia da Universidade de São Paulo, bem como a todos os funcionários que contribuíram para que este trabalho chegasse ao fim.

Gratidão ao Grupo de Pesquisa voltado à Formação de Professores da Rede Pública Municipal de São Paulo. O último dia do encontro nos fez perceber o quanto, para além do discurso, da teoria, tem o chão da escola e o quanto ele nos mobiliza, marca nossas vidas, arranca reflexões, quase a fórceps, por conta da necessidade ética que ampara nossas ações na relação com as crianças e os jovens. Eles, que, muitas vezes, só têm a nós, professores, para contar, para lhes garantir uma vida digna! Vocês contribuíram muito com minhas reflexões!

Agradeço ao Núcleo do Fórum sobre Medicalização por me possibilitar lutar por uma causa tão relevante quanto a que defendemos. Foi a Medicalização uma das justificativas da minha pesquisa. Gratidão a você, Bia Sousa, por estar à frente de um estudo tão consistente sobre a Medicalização na Educação Pública.

Gratidão à Prof ${ }^{\mathrm{a}}$. Dr ${ }^{\mathrm{a}}$. Roseli Caldas, querida, pelo convite para representar a Associação Brasileira de Psicologia Escolar e Educacional (ABRAPEE), no Fórum Municipal de Educação! Tenho aprendido muito nesta tarefa, acompanhar as discussões sobre Educação Pública está sendo muito enriquecedor.

Gratidão ao Prof. Pacheco, por acreditar na criança e no jovem! O senhor foi uma grande inspiração para mim, principalmente, porque desceu do palanque teórico, arregaçou as mangas 
e foi lá, pertinho das crianças e dos jovens, lá onde existe vida concreta, cochichar em seus ouvidos a importância de sua individualidade e de suas diferenças. Mostrou que aproximar a escola da comunidade traz um senso de cooperação que enriquece a vida de todos.

Gratidão ao Projeto Âncora, em especial à coordenadora Edilene Morikawa, pela generosidade e pelo comprometimento com as crianças e os adolescentes. E aos estudantes, que tantas alegrias e descobertas garantiram a mim e ao meu trabalho.

Agradeço aos membros da minha banca: Prof ${ }^{\mathrm{a}}$. Dra. Ana Karina Amorim Checchia, Prof ${ }^{\mathrm{a}}$. Dra . Laura Marisa Carnielo Calejon, Prof ${ }^{\mathrm{a}}$. Dr ${ }^{\mathrm{a}}$. Márcia Regina Cordeiro Bavaresco, Prof $^{\mathrm{a}}$. Dr ${ }^{\mathrm{a}}$. Flávia da Silva Ferreira Asbahr, Prof ${ }^{\mathrm{a}}$. Dr ${ }^{\mathrm{a}}$. Marie-Claire Sekkel, Prof ${ }^{\mathrm{a}}$. Dr ${ }^{\mathrm{a}}$. Mônica Cintrão França Ribeiro. Vocês são pessoas cuja coerência, comprometimento e generosidade justificaram o convite!

Finalmente, e principalmente, gratidão à minha querida orientadora, Prof ${ }^{\mathrm{a}}$. Dr ${ }^{\mathrm{a}}$. Marilene Proença Rebello de Souza, uma pessoa reconhecidamente coerente, guerreira e generosa. Querida, serei eternamente grata a você por defender que não existem barreiras para os que têm sede de conhecimento. Quando me aceitou como sua orientanda, foi como se você viabilizasse realizar minha missão de vida, porque hoje eu não me vejo fazendo outra coisa senão compartilhar aquilo que venho aprendendo com os que, como eu, amam o que fazem. Você possibilitou meu ingresso no universo das Políticas Públicas em defesa de uma causa tão relevante e necessária: a Educação Brasileira, destacando a Educação Pública de qualidade, sobretudo democrática. Você é pessoa ímpar, incansável na luta pelas causas daqueles que não têm voz. Você é um ser humano da maior qualidade! Agradeço por tudo e, principalmente, por você ter acreditado em mim! 
Suplicamos expressamente: não aceiteis o que é de hábito como coisa natural, pois em tempo de desordem sangrenta, de confusão organizada, de arbitrariedade consciente, de humanidade desumanizada, nada deve parecer natural, nada deve parecer impossível de mudar.

Bertolt Brecht 


\section{RESUMO}

MATOS, Lucy Duró Andrade Silva. Reflexões sobre a Educação Crítica e Emancipadora: o Projeto Âncora em questão. 2019. 184 f. Dissertação (Mestrado em Psicologia) - Instituto de Psicologia da Universidade de São Paulo, São Paulo, 2019.

A proposta tradicional de educação é marcada por pressupostos que desconsideram o homem como sujeito histórico; que valorizam a transmissão de conhecimento de forma memorística e acrítica e concebem a escola, sobretudo, como veículo, cuja função é preparar o aluno para o mercado de trabalho. A diversidade cultural e a individualidade com suas características, como preferências e ritmos de aprendizagem, não são levadas em consideração, ou seja, não há respeito ao que cada um traz consigo em seu percurso de vida. Consequentemente, com base nessa lógica, alguns alunos são promovidos e muitos vão ficando pelo caminho, marcando sua história com experiências de fracasso de responsabilidade de outrem. Na maioria das vezes, são encaminhados aos consultórios de profissionais da saúde para possíveis diagnósticos e, em muitos casos, consequente medicalização. Para além da crítica, a Psicologia Escolar e do Desenvolvimento Humano tem apontado caminhos que viabilizam reflexões de modo a superar o modelo instituído, que pretere a potencialidade humana em nome de uma padronização nos modos de ser e de viver e põe em risco um olhar rigoroso sobre as causas do não aprender. Esta pesquisa toma por objeto de estudo o processo de escolarização numa perspectiva pedagógica crítica e emancipadora. Tem por objetivo conhecer uma experiência educacional de Escola Democrática, de forma a compreender aspectos do processo de constituição dos estudantes e a partir das reflexões geradas, analisar a possibilidade de uma formação crítica e emancipadora ser levada a termo. A proposta escolhida foi o Projeto Âncora, organização filantrópica, que vem desenvolvendo um trabalho inspirado na Escola da Ponte, em Vila das Aves, Portugal, com a mentoria de José Francisco de Almeida Pacheco. A pesquisa teve como referencial teórico a Psicologia Histórico-Cultural. O princípio metodológico, Materialismo HistóricoDialético, comunga com a base teórica e permite articulações de modo a revelar o objeto a ser investigado com maior profundidade, buscando-se compreender sua dinâmica em meio ao contexto social. Quanto aos procedimentos metodológicos, partimos de uma análise documental do Projeto Político-Pedagógico e o informativo à comunidade; uma entrevista não estruturada com o mentor do projeto; uma visita à escola conduzida por duas estudantes e a participação em duas Rodas de Conversa realizadas pela escola aos visitantes. No que diz respeito à análise dos dados, apresentamos um diagrama a partir de uma técnica denominada Mind Map, desenvolvida pelo psicólogo inglês Tony Buzan, que nos possibilitou organizar os dados levantados em eixos e subeixos. Os resultados levantados permitiram a compreensão de que é possível, a partir desta perspectiva pedagógica, promover uma gestão participativa e democratizar o conhecimento, possibilitando uma formação crítica e emancipadora, dentro dos limites oferecidos pelo sistema político-econômico e social brasileiro. Propiciar condições para que os estudantes exerçam o protagonismo, no sentido de oferecer espaços comuns de diálogo e participação política, revelou no campo das atitudes que as escolhas e responsabilidades assumidas mobilizam um querer cuidar, promovendo um sentido ao seu viver no contexto social. Oferecer sentido e significado ao conhecimento na relação com a materialidade que se expressa no cotidiano das ações humanas abre um espaço de possibilidades de participação e ganho de autonomia, viabilizando aos estudantes o acesso ao conhecimento.

Palavras-chave: Projeto Âncora. Escolas Democráticas. Psicologia Escolar. Educação. Comunidades de Aprendizagem. 


\begin{abstract}
MATOS, Lucy Duró Andrade Silva. Reflections on a Critical and Emancipatory Education: the Projeto Âncora ${ }^{1}$ in question. 2019. 184 f. Dissertation (Master in Psychology) - Instituto de Psicologia da Universidade de São Paulo², São Paulo, 2019.

The traditional education proposal is marked by presuppositions that disregard the man as historical subject; who value the transmission of knowledge in a memoristic and uncritical way and conceive the school, especially, as a vehicle, whose job is to prepare the student for the market. Cultural diversity and individuality with their characteristics, such as preferences and learning rhythms, are not taken into account, that is, there is no respect for what each one brings with them in their life course. Consequently, considering this logic some students are promoted and many are getting in the way, marking their history with experiences of failure which others are responsible for. Most of the time they are sent to health care professionals for a possible diagnosis and, in many cases, consequent medicalization. In addition to the criticism, School and Human Development Psychology has raised ways to make possible reflections in order to overcome the established model, that disconsider human potentiality in the name of a standardization in the ways of being and living and jeopardizes a rigorous look at the causes of not learning. This research takes as object of study the process of schooling in a critical and emancipatory pedagogical perspective. Its purpose is to understand a Democratic School educational experience, in order to comprehend aspects of the students' constitution process and from the reflections generated, to analyze the possibility of a critical and emancipatory formation being achieved. The proposal chosen was the Projeto Âncora, a philanthropic organization inspired by the Escola da Ponte, in Vila das Aves, Portugal, with the mentorship of José Francisco de Almeida Pacheco. The research had as theoretical reference the HistoricalCultural Psychology. The methodological principle, Historical-Dialectical Materialism, communes with the theoretical basis and allows articulations in order to reveal the object to be investigated in greater depth, seeking to understand its dynamics in the midst of the social context. As for the methodological procedures, we start with a documentary analysis of the Political-Pedagogical Project, the website with information to the community and the letter of principles; an unstructured interview with the project mentor; a visit to the school led by two students and the participation in two chatting circles carried out by the school to the visitors. Regarding the data analysis, we presented diagram using a technique called Mind Map, developed by the British psychologist Tony Buzan, which enabled us to organize the data collected on axes and sub-axes. The results obtained allowed the understanding that it is possible, from this pedagogical perspective, to promote a participatory management and democratize knowledge, enabling a critical and emancipatory formation, within the limits offered by the Brazilian political-economic and social system. Providing conditions for students to play a leading role by offering common spaces for dialogue and political participation has revealed in the field of attitudes that the choices and responsibilities assumed mobilize a desire to care, promoting a meaning to their living in the social context. Offering sense and meaning to the knowledge in its relation to the materiality that is expressed in the human actions daily life opens up a space of possibilities for participation and gain of autonomy, making knowledge access feasible for students.
\end{abstract}

Keywords:. Projeto Âncora. Democratic Schools. School Psychology. Education. Learning Communities.

\footnotetext{
${ }^{1}$ Ancora Project

${ }^{2}$ University of São Paulo
} 


\section{LISTA DE FIGURAS}

FIGURA 01 - Organização Internacional do Trabalho (OIT) ......................... 034

FIGURA 02 - Mapa Mental e os Eixos de Análise......................................... 086

FIGURA 03 - Parte externa do Circo................................................................ 089

FIGURA 04 - Acrobacia.............................................................................. 090

FIGURA 05 - Atividades de Artes Plásticas na parte interna do Circo.............. 090

FIGURA 06 - Reunião com a comunidade, pais, no espaço interno do Circo... 090

FIGURA 07 - Parque Infantil.................................................................... 091

FIGURA 08 - Pista de Skate ................................................................... 091

FIGURA 09 - Sala Multifuncional.............................................................. 091

FIGURA 10 - Sala de Estudos................................................................... 091

FIGURA 11 - Sala de Música................................................................... 092

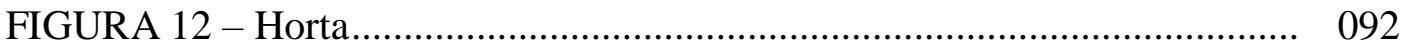

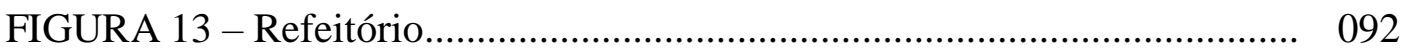

FIGURA 14 - Refeitório.......................................................................... 092

FIGURA 15 - Espaço de Aprendizagem do Nível Iniciação............................ 093

FIGURA 16 - Espaço de Aprendizagem do Nível Iniciação............................ 093

FIGURA 17 - Ateliê de Mosaico.................................................................. 093

FIGURA 18 - Sala Nível Desenvolvimento................................................... 094

FIGURA 19 - Estudante em espaço de livre escolha....................................... 094

FIGURA 20 - Apresentação de Temas............................................................ 094

FIGURA 21 - Imagem panorâmica do Projeto Âncora..................................... 098

FIGURA 22 - Linha do Tempo..................................................................... 099

FIGURA 23 - Avaliações externas aplicadas aos alunos do Projeto Âncora.... 108

FIGURA 24 - A organização de duas modalidades de Educação..................... 114

FIGURA 25 - Roteiro de Estudo.............................................................. 118

FIGURA 26 - OXFAM............................................................ 144 


\section{SUMÁRIO}

APRESENTAÇÃ

A relação entre o meu percurso de vida e a causa que defendo .....................................11

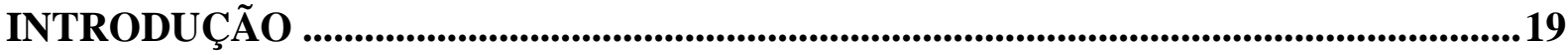

CAPÍTULO I - Educação no Contexto Político-Econômico e Social Brasileiro................29

CAPÍTULO II - Manutenção do Sistema Educacional Hegemônico ....................................41

CAPÍTULO III - Da Palmatória à Ritalina ..........................................................................47

CAPÍTULO IV - Escolas Democráticas e Projeto Âncora...............................................65

CAPÍTULO V - Concepção Metodológica da Psicologia Histórico-Cultural ....................72

CAPÍTULO VI - Procedimento Metodológico .......................................................................80

6.1. Levantamento de dados ...............................................................................................................80

6.2. Organização dos Dados .................................................................................................................8 84

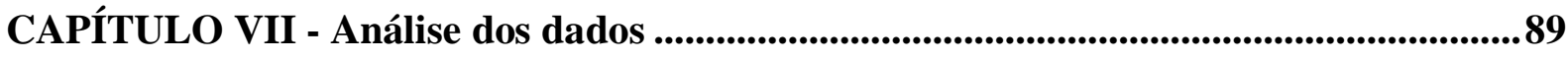

7.1. Projeto Âncora - Apresentação .......................................................................89

7.2. Conhecendo o Projeto Âncora pelo olhar do estudante ..........................................90

7.3. Formação crítica ........................................................................................................97

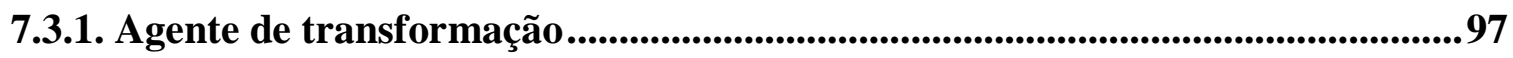

7.3.2. Concepção de Aprendizagem e Concepção de Estudante ..................................109

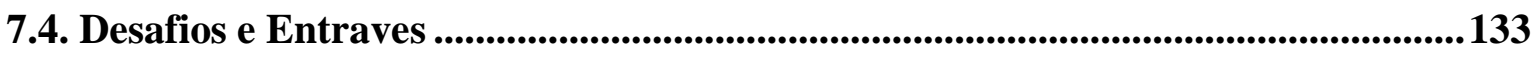

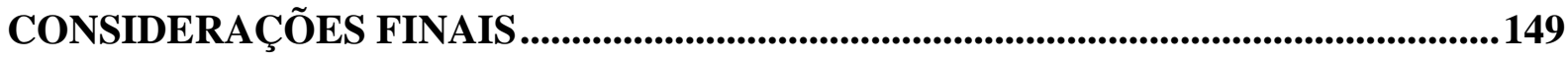

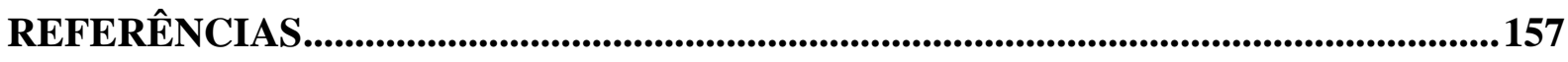

ANEXOS A.......................................................................................................................................... 166

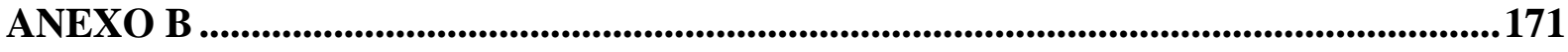

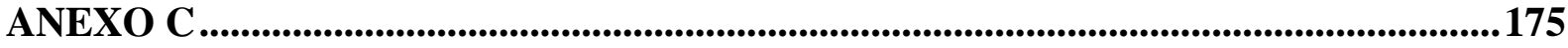

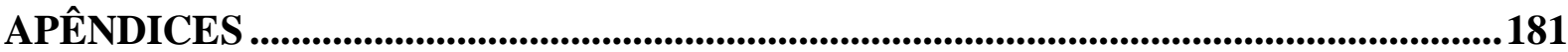

